\title{
IN VITRO EVALUATION OF THE PRECISION OF WORKING CASTS FOR IMPLANT-SUPPORTED RESTORATION WITH MULTIPLE ABUTMENTS
}

\author{
Anderson Almeida CASTILHO ${ }^{1}$, Alberto Noriyuki KOJIMA², Sarina Maciel Braga PEREIRA ${ }^{3}$, Diego Klee de VASCONCELLOS², \\ Marcos Koiti ITINOCHE ${ }^{2}$, Renata FARIA ${ }^{2}$, Marco Antonio BOTTINO ${ }^{4}$
}

\author{
1- Research Fellow, Department of Dental Materials and Prosthodontics, Dental School of São José dos Campos, São Paulo State University \\ "Júlio de Mesquita Filho", São José dos Campos, SP, Brazil. \\ 2- DDS, MS, PhD, Department of Dental Materials and Prosthodontics, Dental School of São José dos Campos, São Paulo State University \\ “Júlio de Mesquita Filho", São José dos Campos, SP, Brazil. \\ 3- MS, Department of Dental Materials and Prosthodontics, Dental School of São José dos Campos, São Paulo State University "Júlio de \\ Mesquita Filho", São José dos Campos, SP, Brazil. \\ 4- DDS, MSc, PhD, Adjunt Professor, Department of Dental Materials and Prosthodontics, Dental School of São José dos Campos, São Paulo
} State University “Júlio de Mesquita Filho”, São José dos Campos, SP, Brazil.

Corresponding address: Anderson Almeida Castilho - Rua Padre José Maria da Silva Ramos, 250, Jardim das Colinas 12242-250, São José dos Campos, SP, Brasil - Phones: 5512 3922-7545/ 3931-8544 - e-mail: andercast@yahoo.com.br

Received: February 02, 2007 - Modification: April 27, 2007 - Accepted: May 14, 2007

\begin{abstract}
$O$

bjective: The purpose of this study was to compare the accuracy of two working cast fabrication techniques using straingauge analysis. Methods: Two working cast fabrication methods were evaluated. Based on a master model, 20 working casts were fabricated by means of an indirect impression technique using polyether after splinting the square transfer copings with acrylic resin. Specimens were assigned to 2 groups $(n=10)$ : Group A (GA): type IV dental stone was poured around the abutment analogs in the conventional way; Group B (GB), the dental stone was poured in two stages. Spacers were used over the abutment analogs (rubber tubes) and type IV dental stone was poured around the abutment analogs in the conventional way. After the stone had hardened completely, the spacers were removed and more stone was inserted in the spaces created. Six strain-gauges (Excel Ltd.), positioned in a cast bar, which was dimensionally accurate (perfect fit) to the master model, recorded the microstrains generated by each specimen. Data were analyzed statistically by the variance analysis (ANOVA) and Tukey’s test ( $\hat{I} \pm=5 \%)$. Results: The microstrain values $(\mu \varepsilon)$ were (mean \pm SD): GA: $263.7 \pm 109.07 \mu \varepsilon$, and GB: $193.73 \pm 78.83 \mu \varepsilon$. Conclusion: There was no statistical difference between the two methods studied.
\end{abstract}

Uniterms: Implant-supported restoration; Molding; Strain gauges.

\section{INTRODUCTION}

Failure of passive fit in implant-supported prostheses induces deleterious forces on the implants and their associated components, and can lead to denture failure by fatigue and/or loss of osseointegration ${ }^{17,20}$. It is recognized that absolute passive fit is unattainable $\mathrm{e}^{11,19}$, as the clinical and laboratory variables inherent to rehabilitating treatment itself are obstacles to this ${ }^{9,7,13}$.

Therefore, the relevance of misfit is considered in view of the materials available and techniques used at present. Branemark, et al. ${ }^{6}$ (1985) has recommended the splinting technique as the clinical conduct of choice for transferring the intraoral posts to the working model. According to this author, this conduct increases the stability of the transfers both during their removal from the impression and at the moment of fixing the analogs, in addition to having shown more consistent results with regard to precision of the impression $^{5,14}$. Moreover, polyether and addition silicone impression materials should be preferred for transfer procedures because they have the lowest distortion values (around $100 \mu \mathrm{m})^{15}$.

The method used for preparation of the working model for implant-supported prostheses should be taken into consideration, as it must be accurate and resistant to dimensional changes ${ }^{4}$. Thus, the expansion of the plaster setting may have a negative influence on positioning the analogs and consequently be a negative factor added to the basic requisites for achieving passive fit. The purpose of this study was to evaluate a variable in the technique used for preparation of working models for manufacturing metal infrastructures (replicas of the abutments were isolated 
with rubber tubes to prevent contact with the plaster inserted, after the intermediates were fixed to the plaster test specimen), by assessing the influence on the passiveness of the denture structure associated with the indirect technique, and the use of polyether for taking impressions under analysis by strain gauges.

\section{MATERIALAND METHODS}

A homogeneous polyurethane-based experimental model was created (Polyurethane for pouring F16; Axson, Cergy, France). Four external hexagon, self-tapping implants measuring $3.75 \mathrm{~mm}$ in diameter by $13.00 \mathrm{~mm}$ in length (Master Screw; 517713; Conexão Sistema de Próteses, São Paulo, SP, Brazil) were screwed to 4 Micro-Unit type prosthetic connections (132023; Conexão Sistema de Próteses, São Paulo, SP, Brazil) 3-mm high, belted, with a torque of $20 \mathrm{Ncm}$ (manual torquemeter 400000; Conexão Sistema de Próteses, São Paulo, SP, Brazil) in accordance with the manufacturer's recommendations. The post/implant sets were fixed to a preexistent palladium-silver based, circular shaped metal bar (Williams W1; Ivoclar Vivadent, Amherst, NY, USA), of 4 mm in the buccolingual direction and 3mm in the occlusocervical direction, at a torque of $10 \mathrm{Ncm}$. This bar was made by the lost wax technique, being over cast on 4 cylinders machined from precious metal (144002; Conexão Sistema de Próteses, São Paulo, SP, Brazil), disposed parallel to each other at a distance of $14 \mathrm{~mm}$ from center to center. By means of quality control of the marginal adaptation of the machined cylinders with an optic microscope at X230 magnification (Sprint 100; RAM Optical Instrumentation; Irvine, CA, USA), components that presented a misfit greater than $10 \mu \mathrm{m}$ in relation to the prosthetic pillars were discarded.

Four parallel holes with slightly larger diameter and length than the implants were previously drilled in the experimental model. The bar/abutments/implants set was fixed to the model by means of re-basing the holes with polyurethane, keeping the abutments to the level of the model surface. Thus, it was sought to diminish the stresses that could be introduced to the bar to the maximum, and thereby minimize the influence on the readings of the strain gauges that would monitor the test specimens.

Four square transfers were screwed to the Micro-Unit type prosthetic connections of the master model at a torque of $10 \mathrm{Ncm}$. To fabricate each test specimen, the transfers were splinted with resin (G.C. Pattern Resin; G.C. Dental Industrial; Tokyo, Japan). Splinting was standardized by following the same standard measurement of the Ag-Pd bar used in the master model, with polyvinylsiloxane duplication material (Stern Tek; Sterngold Restorative Systems, Attleboro, MA, USA), by the powder/liquid brush technique. Twenty ferrules with identical thickness and length were made. After 17 minutes, the ferrules were cut into three parts at equidistant points from the transfers with a 0.5 -mm-thick diamond disk and reunited again with resin by the brush technique.

Twenty impressions were made in polyether material (Impregum F, ESPE, Seefeld, Germany) using the indirect technique by means of an individual mold previously made of chemically activated acrylic resin. Under a constant load of $500 \mathrm{~g}$ for 10 minutes, the impressions were kept in position until the final polymerization reaction of the material. All moldings were done in a temperature controlled environment at $26^{\circ} \mathrm{C}$ and relative humidity of around $50 \%$, maintained by air conditioning and air humidification. Perforations and four top openings were made in the body of the mold to allow free access to the square transfer screws, and in each act of molding, the adhesive for polyether (3M/ESPE, St. Paul, MN, USA) was previously used, and 15 minutes were waited. The standard mold presented internal relief of $2 \mathrm{~mm}$ in both directions for the resin ferrules. The contention walls in the mold fitted intimately to the standard model walls, in order to allow the same positioning and involvement to the base at all times, thus allowing afterwards, when the test specimens were made, that the same quantity of molding material and plaster could be used.

When the mold was obtained, replicas of the intermediates were screwed to the transfers at a torque of $10 \mathrm{~N}$ and before the volume of plaster for making each test specimen was inserted, a $3.5 \mathrm{~cm}$ high dyke of 7 wax (Polidental, Indústria e Comércio Ltda., São Paulo, SP, Brazil) was constructed for each mold, so that the test specimen housed $100 \mathrm{~g}$ of Durone type IV plaster (Dentsply, Petrópolis, RJ, Brazil). The 10 test specimens were divided into two groups (A and B), which differed to each other in the manner of insertion of the plaster.

In Group A, the normal procedure was followed, so that the volume of plaster was inserted in the 10 test specimens in the conventional manner, in accordance with the manufacturer's instructions (water-powder ratio). In Group $\mathrm{B}$, each replica of the abutments was isolated with rubber tubes in order to prevent contact with the plaster inserted for making the test specimens. After the plaster had hardened completely, all rubber tubes were removed, and only then the amount of plaster necessary for fixing the intermediates to the plaster test specimen was inserted, also in accordance with the water/powder ratio recommended by the manufacturer (Figure 1).

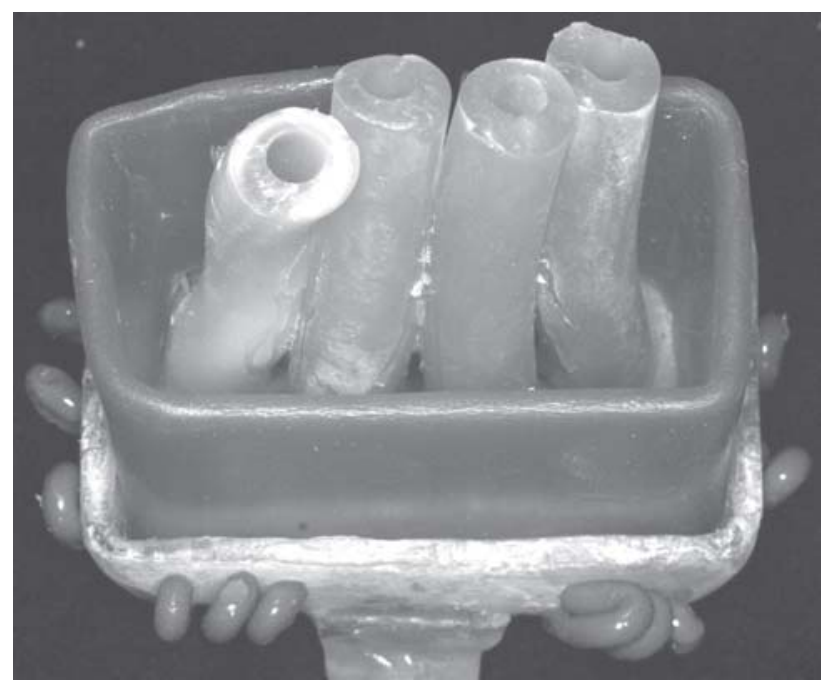

FIGURE 1- Mold with the 7 wax dyke and after relief with rubber tubes 
The water/powder ratio used was suggested by the manufacturer as a guide $(19 \mathrm{~mL}$ water for each $100 \mathrm{~g}$ of plaster), and was measured with a pipette graded for the volume of water and a scale graded for weighing the powder. The mixture was worked with a spatula for 15 seconds in a plastic tub to homogenize it, and mixing complemented by working with a spatula under vacuum for another 1 minute. All test specimens were kept at a constant temperature of $26^{\circ} \mathrm{C}$. A period of 2 hours was waited for the test specimen unmolding procedures and for the micro-deformation readings by means of the strain gauges.

Using the device developed with the metal structure fabricated in Ag-Pd, the 20 test specimens (GA n=10; GB $n=10$ ) were assessed by means of the strain-gauges. The influence of type IV plaster setting expansion on the fabrication of the working models was assessed by means of the traction and compression induced in the test specimens.

Two strain gauges (PA-06-060CA-120L; Excel Sensores Ltda., São Paulo, SP, Brazil) were bonded to the top surface on each segment of the bar with cyanoacrylate adhesive (Super Bonder ${ }^{\circledR}$; Loctite, São Paulo, SP, Brazil), aligned to the fixing screws and $1 \mathrm{~mm}$ distant from their platforms, making a total of 6 strain gauges, which were numbered from 1 to 6 , from left to right. Data from the 6 sensors were amplified and transferred with a signal amplifier (ADS 2000IP; Lynxx, São Paulo, SP, Brazil) and were then recorded and later analyzed by a special software (AqDados \& AqAnalysis; São Paulo, SP, Brazil). The magnitude of deformation in each strain gauge was recorded in microdeformation $(\mu \varepsilon)$, which is equivalent to the change in length of a strain gauge, divided by its original length $(1.52 \mathrm{~mm})$ and multiplied by $10^{-6}$. The appliance was balanced and calibrated to $\pm 000 \mu \varepsilon$ of deformation, without fastening the screws on the analysis device for each reading (Figure 2).

The screw-fastening sequence, after the test specimens were positioned on the analyzing device followed the sequence proposed by $\mathrm{JEMT}^{10}$, that is, 2,4,1,3. For Groups $A$ and $B, 3$ readings were made for each specimen after expansion of the final plaster setting. The deformation produced in each strain gauge was measured and recorded as soon as the four screws were tightened.

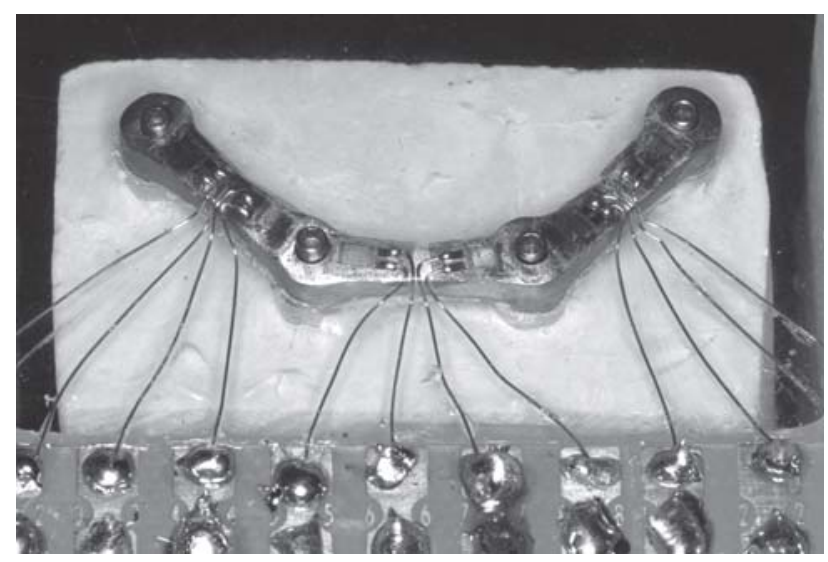

FIGURE 2- Device for analyzing the strain gauges of the test specimens
This experiment followed a factorial scheme of the $2 \times 3$ type. The experimental variables, the factors under study were relief (absence and presence) and the strain gauges (positions: S-12, S-34 and S-56). The variable response was the micro-deformation value obtained in the strain-gauge test. The experimental unit was the prosthetic structure. The test specimens were randomly assigned to the relief (spacers of rubber tubes - SRT) conditions.

Sixty (60) data were obtained, that is, six experimental conditions by six repetitions, which were submitted to statistical analysis using the following statistical softwares MiniTab, version 14.12, 2004(Minitab, Inc., State College, PA, USA) and GraphPad Prism version 4.0, 2003 (GraphPad Software Inc., San Diego, CA, USA). The descriptive statistics consisted of the calculation of the means and standard deviations. The inferential statistics consisted of analysis of variance of repeated measurements of two factors (relief [SRT] and strain-gauges), in which the variable straingauges was considered as a repeated factor. The study of the interaction effect was conducted by means. Multiple comparisons among the means for the 6 experimental conditions were made by the Tukey's multiple-comparison test. Significance level was set at $5 \%$.

\section{RESULTS}

The micro-deformation values $(\mu \varepsilon)$ obtained are shown in the scatter diagram in column (dot plot) (Figure 3).

To assess the relationship between the relief and the position of the strain-gauge, the data obtained in the present experiment were submitted to ANOVA, after the suppositions of the analysis of variance model were assessed.

The residual values, resulting from adjustment of the model adopted, were examined to assess the suitability of the model for valid statistical inferences and it was determined that the original data provided an adequate adjustment because they adjusted to a normal distribution of probability, and the uniformity of the residues (homoscedasticity) was furthermore verified by means of the graph of residual values in relation to the adjusted values.

Data on Table 1 show that only the effect of interaction was statistically significant. There was not the same relation between the conditions (with and without relief - spacers of rubber tubes) in each type of strain-gauge (Figure 4). It is

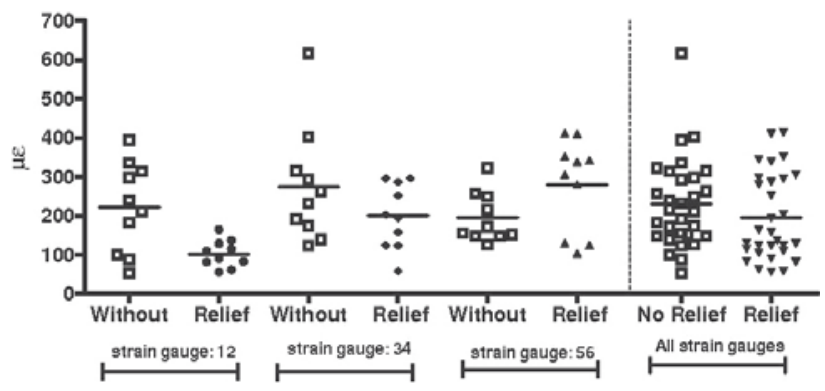

FIGURE 3- Dot plot for micro deformation $(\mu \varepsilon)$ values obtained under the different experimental conditions 
possible to state that the difference between the conditions without relief versus with relief (spacers of rubber tubes) is more severe for the strain-gauge type S1.2.

\section{DISCUSSION}

ADA's No. 25 specification $^{1}$ indicates that the measurements of the final setting expansion of the plaster should be taken two hours after it is mixed, but according to Heshmati, et al. ${ }^{8}$ (2002), higher linear expansion values were found at 120 hours rather than at 2 hours, with $22 \%$ to $71 \%$ of the total setting expansion occurring after 2 hours. Furthermore, total expansion was completed within 96 hours. According to Winkler, et al. ${ }^{23}$ (1998), plaster setting time depends on the measuring method and the setting of plaster in terms of clinical relevance is affected in any case before its final setting, altering its microscopic structure. The clinical relevance of these data are reflected in the fact that the quality of fabrication of prosthetic restorations is also related to the quality of the working models obtained.
Weakened models that are easily abraded or distorted have an influence on the rehabilitative treatment. Thus, it is desirable to select a brand of plaster that exhibits expansion patterns and well-defined stability, which must be considered when selecting the commercial brand ${ }^{23}$.

Spiekermann, et al. ${ }^{21}$ (1995) and Rubo and Souza ${ }^{18}$ (2001) described the strain-gauge, photoelasticity and finite elements analysis as the main investigation and biomechanical analysis methods in implant dentistry.

In the present study using strain-gauge testing, the micro-deformation values were obtained 2 hours after the test specimens were fabricated, in accordance with the ADA's No. 25 specification, in which the final setting expansion of the plaster and its possible effect on displacement of the analogs could occur.

In this study, the powder/liquid brush technique was used. According to Takahashi, et al. ${ }^{22}$ (1999), when adequately performed, this technique determines lower indices of resin polymerization shrinkage. Mojon, et al. ${ }^{16}$ (1990) have stated that the dimensional behavior of resin,

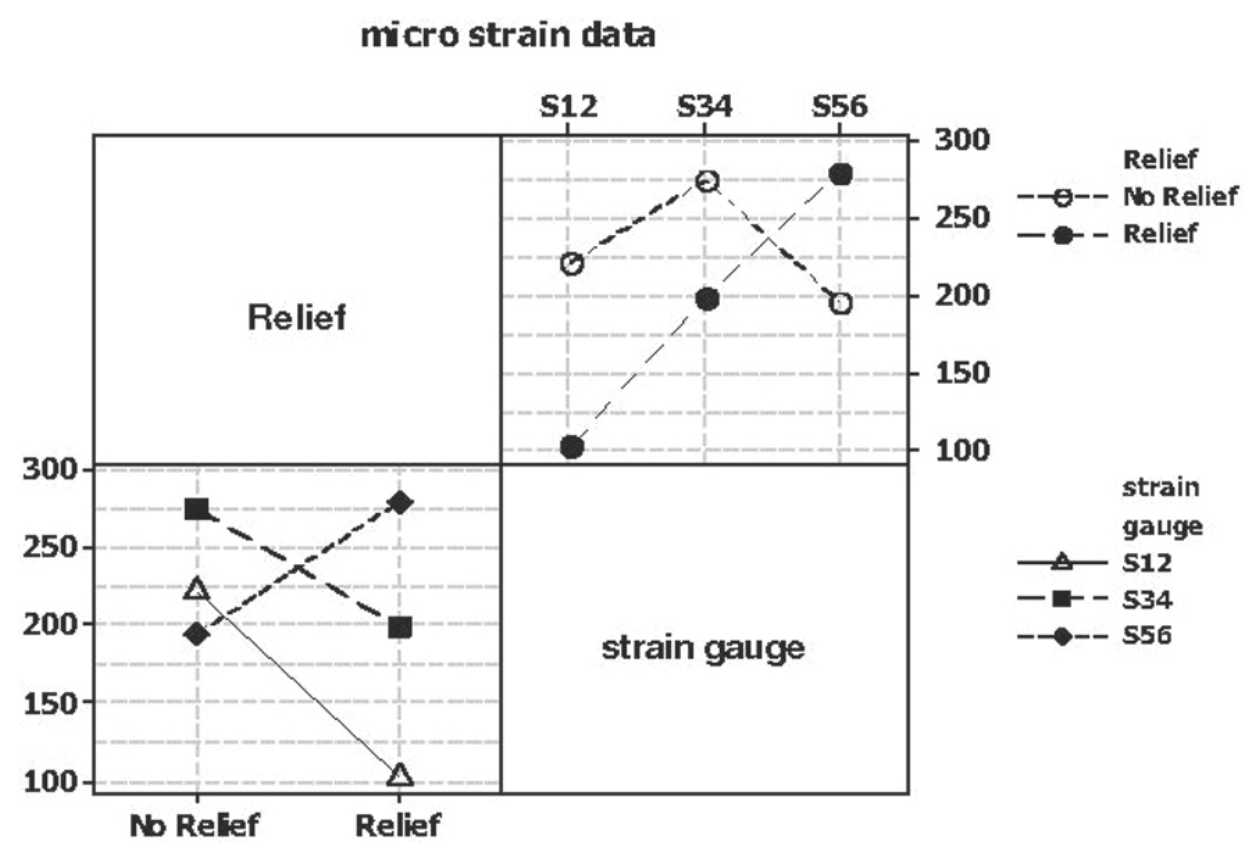

FIGURE 4- Plot of microstrain means values $(\mu \varepsilon)$ by six experimental conditions

TABLE1- ANOVA results for the micro-deformation $(\mu \varepsilon)$ data obtained

\begin{tabular}{|c|c|c|c|c|c|}
\hline Effect & df & ss & MS & $\mathbf{F}$ & $\mathbf{P}$ \\
\hline Relief & 1 & 20131.1 & 20131.1 & 1.83 & 0.1928 \\
\hline Residue I & 18 & 197947 & 1099.1 & & \\
\hline Strain gauge & 2 & 75521 & 37760.7 & 3.84 & 0.0307 \\
\hline Interaction & 2 & 115801 & 57900.3 & 5.89 & $0.0061^{*}$ \\
\hline Residue II & 36 & 353631 & 9823.1 & & \\
\hline Total & 59 & 763031 & & & \\
\hline
\end{tabular}

${ }^{*} \mathrm{p}<0.05$ 
when separation and re-uniting are done 17 minutes after the setting reaction, allows considerable reduction (80\%) in the effects of polymerization shrinkage, within a period of time that would dispense with the second clinical appointment.

The literature is not unanimous as regards which the best molding technique ${ }^{2,3,9}$. Thus, choosing the indirect technique with use of square splinted transfers and following the technique consolidated by Branemark ${ }^{6}$ (1985), limited the influence on the study outcomes. This made possible for all analogs to be positioned in the mold under the same torque, prevented the analogs from rotating while they were being screwed to the square transfers, and also allowed controlling the relationship of the transfers with the molding material. It is assumed that this approach diminished movement during the positioning of the analog replicas.

There are no scientifically based studies referring to modifications in the conventional technique for fabrication of working casts in implant dentistry. In the present study, there was no statistically significant difference between the techniques for preparation of working casts with and without relief. The modified technique with relief did not contribute significantly to the reduction in the mean micro-deformation values, compared to the conventional plaster insertion technique. Only the interaction effect was statistically significant and for each strain-gauge. Although the condition without relief did not differ significantly from the condition with relief, in Sensor S1-S2 the difference between the condition with relief and without relief was more marked (rubber spacers).

From the results of ANOVA and Figure 2, it is possible to state that the difference between the conditions without relief versus with relief followed the same pattern of microdeformation for the strain-gauges type S1-S2 and S3-S4, but differed from the conditions of strain gauges S5-S6.

Data on Table 2 indicates that the causal effect of the differences in the micro-deformation values obtained was the fact that the sensors (S1-S2 and S5-S6) were placed at the extremities of the bar, and underwent greater effects from the tightening sequence of the screws and the plaster setting expansion. Another hypothesis with regard to the condition of the samples with relief, would be the possibility of the pure residual stress having manifested itself more clearly because its condition of relief did not allow the setting expansion process to influence the results of the readings of strain-gauges S5 and S6. Thus, for didactic effect, the metal bar was divided into three segments (A-S1 and S2, BS3 and S4 and C-S5 and S6). After the torque of screws 2 and 4, the bar was stabilized at two points. After the torque of screw 1 , stress was started in segment $A$, since segments $\mathrm{B}$ and $\mathrm{C}$ were stabilized by the torque on screws 2 and 4 . After the torque on screw 3, the strain-gauges 5 and 6 were those that most underwent deformation, since screws 1 and 2 and 4 had already been tightened, giving the set greater stability, sensitizing the strain-gauges S5 and S6 that obtained higher micro-deformation value records. Further studies are required with regard to the condition of relief in working models for implant-supported dentures, as well as with respect to the tightening sequence of denture retention screws.

\section{CONCLUSION}

The search for excellence in passive fit of prosthetic work must be allied to the knowledge provided by applied research in order to guide the choice for the best techniques and materials, with clinical practice information and the sensitivity of each professional's experience. Considering control of the effects of plaster expansion setting that may contribute to displacement of the analogs, the modified technique for fabricating working models was not significantly different or more precise than the technique in which plaster insertion was done in a single stage, which indicates the advantage of ferruling transfers. Further investigation is necessary to quantify the degree of adaptation to prevent biological and/or mechanical complications in implant-supported prostheses.

\section{REFERENCES}

1- American Dental Association. Guide to dental materials and devices. 8th ed. Chicago: The Association; 1976.

2- Assif D, Marshak B, Nissan J. A modified impression technique for implant-supported restoration. J Prosthet Dent. 1994;71(6):58991.

3- Assif D, Marshak B, Schmidt A. Accuracy of implant impression techniques. Int J Oral Maxillofac Implants. 1996;11(2):216-22.

TABLE 2- Homogeneous groups established by Tukey's test (5\%) for the experimental conditions

\begin{tabular}{|c|c|c|c|c|}
\hline Relief & Strain gauge & Mean & SD & Homogeneous Groups \\
\hline Without & S $1-2$ & 221.35 & 115.7 & $A B$ \\
\hline Without & S 3-4 & 275.11 & 147.5 & $A$ \\
\hline Without & S 5-6 & 194.64 & 64.0 & $A B$ \\
\hline With & S $1-2$ & 102.40 & 34.7 & B \\
\hline With & S 3-4 & 199.02 & 83.2 & $A B$ \\
\hline With & S 5-6 & 279.77 & 118.0 & $A$ \\
\hline
\end{tabular}


4- Bailey JH, Donovan TE, Preston JD. The dimensional accuracy of improved dental stone silverplated, and epoxi stone die materials. J Prosthet Dent. 1988;59(3):307-10.

5- Barret MG, de Rijk WG, Burgess JO. The accuracy of six impression techniques for osseointegrated implants. Int J Prosthodont. 1993;2(2):75-82.

6- Branemark PI, Zarb GA, Albrektsson T. Tissue-integrated prostheses: osseointegration in clinical dentistry. Chicago: Quintessence; 1985.

7- Gulbransen HJ. Current issues forum: how do you test a cast framework fit for a full-arch fixed implant-supported prosthesis? Int J Oral Maxillofac Implants. 1994;9(4):472-3.

8- Heshmati RH, Nagy WW, Wirth CG, Dhuru VB. Delayed linear expansion of improved dental stone. J Prosthet Dent. 2002;88(1):26 31 .

9- Hsu C, Millstein PL, Stein RS. A comparative analysis of the accuracy of implant transfer techniques. J Prosthet Dent. 1993;69(6):588-93.

10- Jemt T. Failures and complications in 391 consecutively inserted fixed prostheses supported by Branemark implants in edentulous jaws: a study of treatment from the time of prosthesis placement to the first annual checkup. Int $\mathrm{J}$ Oral Maxillofac Implants. 1991;6(3):270-6.

11 - Jemt T. Current issues forum: how do you test a cast framework fit for a full-arch fixed implant-supported prosthesis? Int J Oral Maxillofac Implants. 1994;9(4):471-2.

12- Jemt T. In vivo measurements of precision of fit involving implant-supported prostheses in edentulous jaw. Int J Oral Maxillofac Implants. 1996;11(2):151-8.

13- Kano SC. Avaliação da adaptação da interface intermediário/ cilindro de ouro e da compatibilidade de diferentes sistemas de implantes odontológicos: análise intra e entre sistemas [dissertação]. Bauru (SP): Faculdade de Odontologia de Bauru, Universidade de São Paulo; 1998

14- Liou AD, Nicholls JI, Yuodelis RA, Brudvik JS. Accuracy of replacing three tapered transfer impression copings in two elastomeric impression materials. Int J Prosthodont. 1993;6(4):377-83.

15- Lorenzoni M. Comparison of the transfer precision of three different impression materials in combination with transfer caps for the frialit-2 system. J Oral Rehabil. 2000;27(7):629-38.

16- Mojon P, Oberholzer JP, Meyer JM, Belser UC. Polymerization shrinkage of index and pattern acrylic resins. J Prosthet Dent. 1990;64(6):684-8.

17- Rangert B, Jemt T, Jorneus L. Forces and moments on Branemark implants. Int J Oral Maxillofac Implants.1989;4(3):241-7.

18- Rubo JH, Souza EAC. Computational methods applied to bioengineering: solution of load problems in implant prosthesis. Rev Fac Odontol Bauru. 2001;9(3/4):97-103.

19- Sahin S, Cehreli M. The significance of passive framework fit in implant prosthodontics: current status. Implant Dent. 2001;10(2):8592.

20- Skalak R. Biomechanical considerations in osseointegrated prostheses. J Prosthet Dent. 1983;49(6):843-8.

21- Spiekermann H. Biomechanics. In: Color atlas of dental medicine implantology. New York: Thieme Medical Publishers; 1995. p. 8190.
22 - Takahashi J, Kitahara K, Teraoka F, Kubo F. Resin pattern material with low polymerization shrinkage. Int $\mathrm{J}$ Prosthodont. 1999;12(4):325-9.

23- Winkler MM, Monaghan P, Gilbert JL, Lautenschlager EP. Comparison of four techniques for monitoring the setting kinetics of gypsum. J Prosthet Dent. 1998;79(5):532-6. 